\title{
Genetic polymorphisms of nerve growth factor receptor (NGFR) and the risk of Alzheimer's disease
}

\author{
Hui-Chi Cheng', Yu Sun², Liang-Chuan Lai ${ }^{3}$, Shih-Yuan Chen ${ }^{1}$, Wen-Chung Lee ${ }^{1,4,5}$, Jen-Hau Chen ${ }^{1,6}$, Ta-Fu Chen $^{7}$, \\ Hua-Hsiang Chen', Li-Li Wen ${ }^{8}$, Ping-Keung Yip ${ }^{9}$, Yi-Min Chu ${ }^{10}$, Wei J Chen ${ }^{1,4,5}$ and Yen-Ching Chen ${ }^{1,4,5^{*}}$
}

\begin{abstract}
Background: Loss of basal forebrain cholinergic neurons is attributable to the proapoptotic signaling induced by nerve growth factor receptor (NGFR) and may link to Alzheimer's disease (AD) risk. Only one study has investigated the association between NGFR polymorphisms and the risk of AD in an Italian population. Type 2 diabetes mellitus (DM) may modify this association based on previous animal and epidemiologic studies.
\end{abstract}

Methods: This was a case-control study in a Chinese population. A total of 264 AD patients were recruited from three teaching hospitals between 2007 to 2010; 389 controls were recruited from elderly health checkup and volunteers of the hospital during the same period of time. Five common (frequency $\geq 5 \%$ ) haplotype-tagging single nucleotide polymorphisms (htSNPs) were selected from NGFR to test the association between NGFR htSNPs and the risk of $A D$.

Results: Variant NGFR rs734194 was significantly associated with a decreased risk of AD [GG vs. TT copies: adjusted odds ratio $(\mathrm{OR})=0.43$, 95\% confidence interval $(\mathrm{Cl})=0.20-0.95]$. Seven common haplotypes were identified. Minor haplotype GCGCG was significantly associated with a decreased risk of AD ( 2 vs. 0 copies: adjusted OR $=0.39,95 \%$ $\mathrm{Cl}=0.17-0.91)$. Type $2 \mathrm{DM}$ significantly modified the association between rs2072446, rs741072, and haplotype GCTTG and GTTCG on the risk of AD among ApoE $\varepsilon 4$ non-carriers ( $\left.P_{\text {interaction }}<0.05\right)$.

Conclusion: Inherited polymorphisms of NGFR were associated with the risk of AD; results were not significant after correction for multiple tests. This association was further modified by the status of type 2 DM.

Keywords: NGFR, Alzheimer's disease, htSNP, haplotype

\section{Introduction}

Dementia is a degenerative brain syndrome characterized by decline or loss in cognitive function [1]. About 30 million elders suffered from dementia worldwide in 2008 estimated by Alzheimer's Disease International. Alzheimer's disease (AD) is the most common causes of dementia and was the fifth leading cause of death for those aged 65 or older in the United States in 2006 [1]. In Taiwan, more than 160,000 people were demented in 2009 [2] and the number of AD patients keeps raising in many aging populations.

\footnotetext{
* Correspondence: karenchen@ntu.edu.tw

${ }^{1}$ Institute of Epidemiology and Preventive Medicine, College of Public Health, National Taiwan University, Taipei, Taiwan

Full list of author information is available at the end of the article
}

Degeneration of basal forebrain cholinergic neurons (BFCN) has shown to modulate cognitive function in AD patients [3,4]. Nerve growth factor receptor (NGFR, also called $\mathrm{p} 75^{\mathrm{NTR}}$ ) is one of the receptors of NGF and is expressed at the end of cholinergic axon $[5,6]$. The gene encoding NGFR is located on chromosome 17q21-q22. In normal brain, NGFR regulates tyrosine kinase receptor type 1 (TrkA), another receptor of NGF, and induces the signaling of neuronal cell survival $[7,8]$. In contrast, in AD brain, NGFR acts as a proapoptotic receptor in neuron cell death via binding to amyloid-beta $(A \beta), N G F$, or proNGF $[9,10]$. As a whole, NGFR plays multiple roles (survival and apoptosis) in human brain, dependent on the cellular context.
C Biomed Central 
So far, only one study assessed the association between NGFR genetic polymorphisms and the risk of AD in an Italian population [11]. Cozza et al. found that variant rs2072446 was associated with a significantly decreased risk of familial AD [additive model: odds ratio $(\mathrm{OR})=$ 0.28 ] [11]. However, no association was observed for other NGFR SNPs (rs741072, rs2072446, rs2072445, and rs734194) and the risk of sporadic AD [11]. In addition, type $2 \mathrm{DM}$ has been related to the change of NGFR expression in rat brain [12] and cognitive impairment and dementia in the elderly [13-15]. However, no study has explored how type $2 \mathrm{DM}$ affects the association of NGFR polymorphisms with the risk of AD.

NGFR plays an important role in neuronal survival and apoptosis, which may be related to AD pathogenesis. However, only one study explored the association between sequence variants of NGFR and $\mathrm{AD}$ in a Caucasian population. Therefore, we hypothesized that NGFR genetic polymorphisms were associated with the risk of AD in Chinese population. In addition, NGFR may involve in diabetic encephalopathy through neuronal apoptosis. Therefore, this study further investigated how type $2 \mathrm{DM}$ modified the association of NGFR genetic polymorphisms with the risk of $\mathrm{AD}$.

\section{Materials and methods Study Population}

This was a case-control study. A total of 295 sporadic AD patients were recruited from neurology clinic of three teaching hospitals in northern Taiwan from 2007 to 2010. Healthy controls $(n=406)$ were recruited from elderly health checkup and volunteers during the same period of time. All participants were Chinese aged 60 years or older. Participants with the following diseases were excluded: hemorrhagic stroke, organic brain tumor, central nervous system diseases (e.g., Parkinson's disease), depression, cerebral infarction, and dementia other than AD (e.g., vascular dementia and mixed-type dementia, etc.). This study was approved by the institutional review board of each hospital and College of Public Health, National Taiwan University. Written informed consent was obtained from each study participant. The consent from the legal guardian/next of kin was obtained when patients had serious cognitive impairment.

A questionnaire was administered to collect information on demography, comorbidity (e.g., DM and stroke), life style (e.g., cigarette smoking, alcohol, tea or coffee consumption, and exercise); and family history. Blood sample was collected in a tube containing EDTA from each participant. Genomic DNA was extracted by using QuickGene-Mini80 kit (Fujifilm, Tokyo, Japan). After further exclusion of participants without blood samples, a total of sporadic 264 AD patients and 389 controls were included for data analysis.

\section{Dementia Evaluation}

This study included only late-onset (age $\geqq 60$ ) non-familial AD. One neurologist at each hospital performed clinical examination to screen potential dementia cases. MiniMental State Examination (MMSE) [16] and Clinical Dementia Rating (CDR) [17] were used to access their cognitive function. The diagnosis of dementia was done by using Diagnostic and Statistical Manual of Mental Disorders, Fourth edition (DSM-IV) [18]. Head images, computed tomography and magnetic resonance imagings, were taken to exclude organic lesions. Diagnosis of AD was further determined by National Institute of Neurological and Communicative Diseases and Stroke - Alzheimer's Disease and Related Disorders Association (NINCDSADRDA) Alzheimer's Criteria [19]. Short Portable Mental Status Questionnaire [20] was used to assess cognitive function in controls to exclude participants with possible dementia and other mental disorders.

\section{Selection of Single Nucleotide Polymorphisms (SNP) and Genotyping Assay}

Eleven common SNPs (frequency $\geqq 5 \%$ ) in NGFR were identified by using Han Chinese Beijing, China (CHB) genotype data from the International HapMap Project http://hapmap.ncbi.nlm.nih.gov/. Modified Gabriel et al. algorithm $[21,22]$ was used to define haplotype block by using Haploview program http://www.broadinstitute.org/ haploview/haploview. A total of 5 htSNPs (rs2072445, rs2072446, rs734194, rs741072, and rs741073) with an $\mathrm{r}^{2}$ of 0.87 were selected in NGFR gene by tagSNP program [23] (Table 1). Five SNPs spanning NGFR formed one block.

Genotypes of NGFR and Apolipoprotein E (ApoE \&4) SNPs (rs429358 and rs7412) were determined by TaqMan $^{\circledR}$ Genomic Assays [24] using ABI 7900 HT fast realtime PCR system (Applied Biosystems, CA, USA). Genotyping success rate was greater than $95 \%$ for each SNP. Duplicate of $5 \%$ internal samples were selected for quality control purpose and the concordance rate reached 100\% for each SNP.

\section{Statistical Analyses}

Comparison of demographic characteristics between cases and controls were examined by using Student's t tests for normally-distributed continuous variables and chi-square tests for categorical variables.

Hardy-Weinberg equilibrium (HWE) test was performed for each SNP among controls to check genotyping error and selection bias. Partition-ligation-expectation-maximization algorithm was utilized to estimate haplotype frequencies by using tagSNP program [23].

To control for the confounding effect of age, frequency matching was used to match cases and controls on age within an interval of 5 years. The multivariate 
Table 1 Characteristics of the study population

\begin{tabular}{|c|c|c|}
\hline & $\begin{array}{l}\text { Alzheimer's disease } \\
(\mathrm{n}=264)\end{array}$ & $\begin{array}{r}\text { Controls } \\
(\mathrm{n}=389)\end{array}$ \\
\hline & \multicolumn{2}{|c|}{ Mean \pm SD } \\
\hline \multirow[t]{2}{*}{ Age (years) } & $79 \pm 7$ & $73 \pm 6$ \\
\hline & \multicolumn{2}{|l|}{ n (\%) } \\
\hline Female & $172(65 \%)$ & 207 (53\%) \\
\hline \multicolumn{3}{|l|}{ Education } \\
\hline Elementary & $132(50 \%)$ & $40(10 \%)$ \\
\hline High school & $93(35 \%)$ & 160 (41\%) \\
\hline College and above & $39(15 \%)$ & 189 (49\%) \\
\hline \multicolumn{3}{|l|}{ Cigarette smoking } \\
\hline Never & 204 (77\%) & 321 (83\%) \\
\hline Former & $42(16 \%)$ & $56(14 \%)$ \\
\hline Current & $18(7 \%)$ & $12(3 \%)$ \\
\hline \multicolumn{3}{|l|}{ Alcohol consumption } \\
\hline Never & $230(87 \%)$ & 349 (90\%) \\
\hline Former & $24(9 \%)$ & $13(3 \%)$ \\
\hline Current & $10(4 \%)$ & $27(7 \%)$ \\
\hline Type 2 diabetes & $48(18 \%)$ & $51(13 \%)$ \\
\hline Hypertension & 103 (39\%) & 205 (53\%) \\
\hline Hyperlipidemia & $48(18 \%)$ & 115 (30\%) \\
\hline ApoEs '4 carriers & 107 (40\%) & 55 (14\%) \\
\hline
\end{tabular}

Abbreviation: ApoE, Apolipoprotein E gene; SD, standard deviation.

conditional logistic regression models were performed to estimate SNP- and haplotype-specific odds ratio (OR) and $95 \%$ confidence intervals $(\mathrm{CI})$ for $\mathrm{AD}$ in participants carrying either 1 or 2 versus 0 copies of minor allele of each SNP and each multilocus haplotype. Potential confounders adjusted in the models included age, sex, and $A p o E \& 4$ status. Stratified analyses were performed by $A p o E$ \&4 status [25,26] and sex [27,28] because they have been related to the risk of $\mathrm{AD}$. To control for type I error, the false discovery rate (FDR) and the single multiple-degree-of-freedom global test for the association between NGFR haplotypes and the risk of AD was performed. Given a significant global test, haplotypespecific tests can provide some guidance as to which variant(s) contribute to the significant global test.

Vascular risk factors (type 2 DM, hypertension, and hyperlipidemia) and $A p o E \& 4$ status were known risk factors of dementia. Likelihood ratio test was used to evaluate the effect modification by each vascular risk factor on the association between NGFR polymorphisms and the risk of $\mathrm{AD}$ by comparing the model with main effects and interaction terms to the model with main effects only under the assumption of dominant model. Stratified analysis by type $2 \mathrm{DM}$ status or ApoE $\varepsilon 4$ status was performed to estimate OR for NGFR genetic polymorphisms and the risk of AD. All statistical tests were two-sided. SAS version 9.1 (SAS Institute, Cary, NC, USA) was used for statistical analyses.

\section{Results}

Characteristics of study population

A total of 264 AD cases and 389 controls were recruited in this study. As compared with controls, AD cases were older (79 vs. 72 years old), included more women (65\% vs. 53\%), had a lower education level (elementary school: 50 vs. 10 years), more with the history of type $2 \mathrm{DM}$ (18\% vs. $13 \%)$, fewer with the history of hypertension (39\% vs. $53 \%)$ or hyperlipidemia (18\% vs. $30 \%)$, and more were ApoE \&4 carriers (40\% vs. $14 \%$, Table 1 ).

\section{Haplotype-tagging SNPs in NGFR}

Five htSNPs were selected from 11 common (frequency $\geqq 5 \%$ ) SNPs spanning NGFR formed one block, which was determined by the modified Gabriel et al. algorithm $[21,22]$ (Figure 1). None of the NFGR SNPs was out of HWE (Table 2). The internal quality-control specimens did not show evidence of genotyping error as well. The minor allele frequencies (MAFs) of rs734194 (0.19 vs. 0.29 ) and rs741072 (0.41 vs. 0.30$)$ were slightly different between HapMap data and our controls. Other SNPs (rs2072445 and rs2072446) showed similar frequencies.

\section{NGFR SNPs and AD risk}

Variant rs734194 was significantly associated with a decreased risk of $\mathrm{AD}$ (GG vs. $\mathrm{TT}$ : $\mathrm{OR}=0.43,95 \% \mathrm{CI}=$ 0.20-0.95) (Table 3). rs734194 remained significantly associated with an increased risk of AD under the assumption of additive model $(\mathrm{OR}=0.71,95 \% \mathrm{CI}=$ 0.52-0.98, data not shown). After controlling for FDR, no significant association was observed for NGFR SNPs and the risk of AD.

\section{NGFR haplotypes and AD risk}

Seven common (frequency $\geq 5 \%$ ) haplotypes, composed by $5 \mathrm{htSNPs}$, were identified with a cumulative frequency of $97.3 \%$ in controls (Figure 1 \& Table 4). Figure 1 demonstrated the LD structure by using the genotype data of controls in this study. The global $P$ for the association between haplotypes and the risk of $\mathrm{AD}$ was 0.27 . Participants carrying two copies of the minor Hap1 GCGCG had a significantly decreased risk of AD (OR = $0.39,95 \% \mathrm{CI}=0.17-0.91)$. No haplotype was associated with $\mathrm{AD}$ risk under the assumption of additive model (data not shown). After correction for multiple tests by using FDR, significant association between NGFR polymorphisms and AD risk did not retain.

\section{Effect of ApoE $\varepsilon 4$ status}

The ApoE \&4 carriers had a significantly increased risk of $\mathrm{AD}(\mathrm{OR}=4.45,95 \% \mathrm{CI}=2.93-6.75)$ after adjusting for age and sex. The significant association remained after stratified by sex (male: $\mathrm{OR}=3.45,95 \% \mathrm{CI}=1.82-6.56$; 


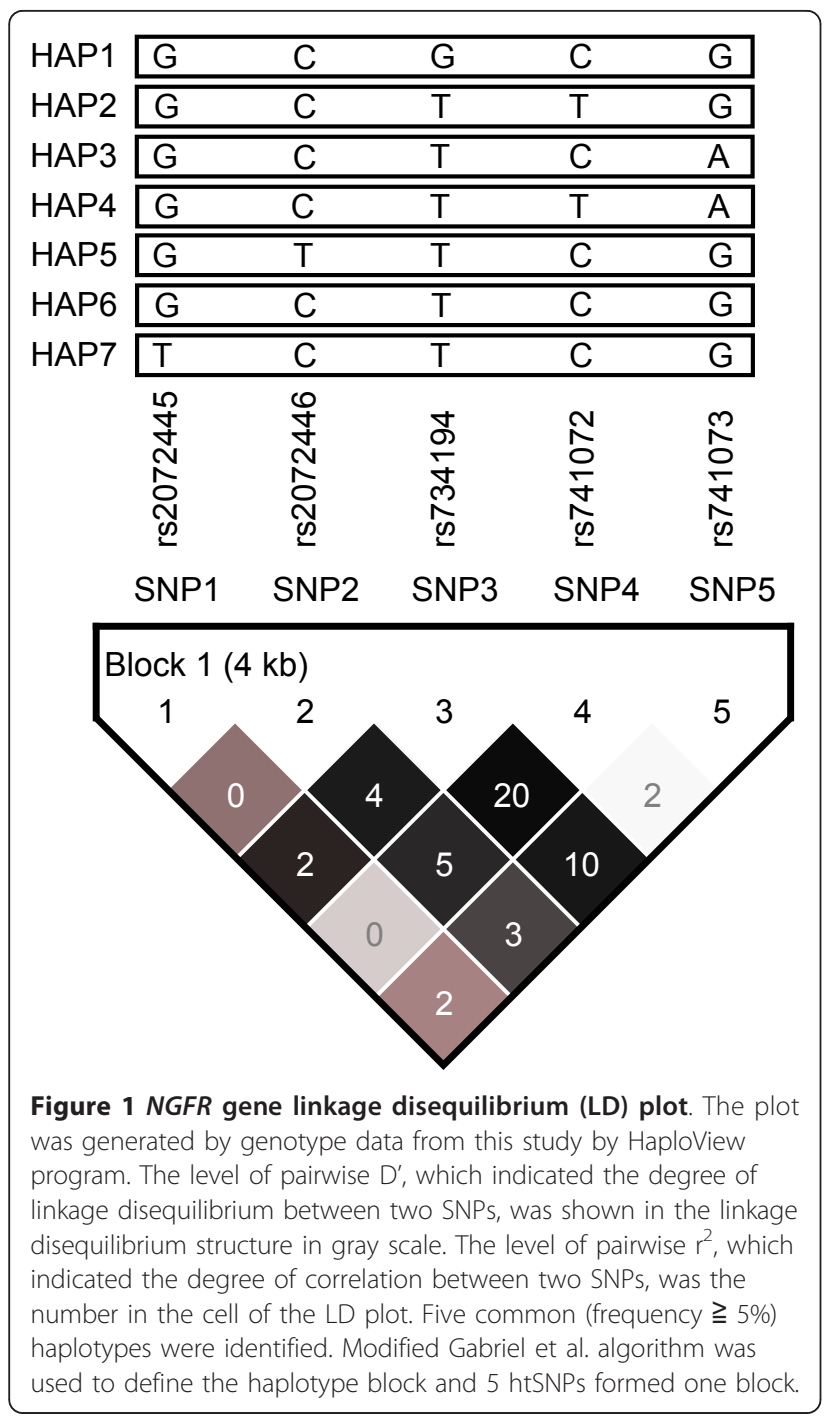

female: $\mathrm{OR}=6.00,95 \% \mathrm{CI}=3.38-10.62$, data not shown).

\section{Effect modification by vascular risk factors}

Among the vascular risk factors (hypertension, type 2 DM, and hyperlipidemia), type $2 \mathrm{DM}$ was the only factor significantly modifying the association between NGFR polymorphisms (rs2072446, rs741072, Hap2, and Hap5) and the risk of $\mathrm{AD}$. After stratification by type $2 \mathrm{DM}$ status, significant associations were observed in some subgroups. Because ApoE $\& 4$ status is an important risk factor for $\mathrm{AD}$, we assess the effect modification by type 2 DM for $A p o E \varepsilon 4$ carriers and non-carriers separately.

For NGFR SNPs, in ApoE \&4 non-carriers without type 2 $\mathrm{DM}$, variant rs2072446 was associated with an increased risk of $\mathrm{AD}(\mathrm{TT}+\mathrm{TC}$ vs. $\mathrm{CC}: \mathrm{OR}=2.18,95 \% \mathrm{CI}=1.19$ 4.00) (Table 5). In contrast, variant rs734194 was associated with a decreased risk of $\mathrm{AD}(\mathrm{OR}=0.28,95 \% \mathrm{CI}=$ 0.08-0.98, Table 5) among diabetic ApoE $\varepsilon 4$ non-carriers. Significant interactions were observed between type $2 \mathrm{DM}$ and NGFR rs2072446 and rs741072 on the risk of AD among ApoE \&4 non-carriers ( $P_{\text {interaction }}=0.007$ and 0.04 , Table 5). Except the interaction between type $2 \mathrm{DM}$ and NGFR rs2072446 among ApoE \&4 non-carriers, other results were not significant after controlling for FDR.

For NGFR haplotypes, among ApoE $\varepsilon 4$ non-carriers, diabetic patients carrying minor Hap1 GCGCG had a decreased risk of AD ( 1 or 2 copies vs. 0 copies: $\mathrm{OR}=$ $0.28,95 \% \mathrm{CI}=0.08-0.97$, Table 6 ). In addition, among ApoE $\varepsilon 4$ non-carriers, non-diabetic patients carrying minor Hap5 GTTCG were associated with a 2.12-fold increased risk of AD (95\% CI $=1.13-3.99$, Table 6). Among ApoE $\varepsilon 4$ non-carriers, type 2 DM significantly modified the association of Hap2 and Hap5 with AD risk

Table 2 Characteristics of NGFR haplotype-tagging SNPs

\begin{tabular}{|c|c|c|c|c|c|}
\hline & SNP1 & SNP2 & SNP3 & SNP4 & SNP5 \\
\hline & rs2072445 & $\begin{array}{l}\text { rs2072446 } \\
\text { (Ser205Leu) }\end{array}$ & rs734194 & rs741072 & rs741073 \\
\hline Nucleotide change & $\mathrm{G} \rightarrow \mathrm{T}$ & $C \rightarrow T$ & $\mathrm{~T} \rightarrow \mathrm{G}$ & $C \rightarrow T$ & $\mathrm{G} \rightarrow \mathrm{A}$ \\
\hline Location & Intron & Exon & 3'UTR & $3^{\prime} U T R$ & 3'UTR \\
\hline \multicolumn{6}{|l|}{ HapMap CHB } \\
\hline MAF & 0.09 & 0.15 & 0.19 & 0.41 & 0.25 \\
\hline \multicolumn{6}{|l|}{ Controls } \\
\hline MAF & 0.07 & 0.11 & 0.29 & 0.30 & 0.24 \\
\hline HWE $P$ value & 0.13 & 0.66 & 0.97 & 0.35 & 0.12 \\
\hline \multicolumn{6}{|l|}{ Cases } \\
\hline MAF & 0.08 & 0.11 & 0.25 & 0.34 & 0.25 \\
\hline HWE $P$ value & 0.17 & 0.72 & 0.57 & 0.21 & 0.37 \\
\hline
\end{tabular}

Abbreviations: HWE, Hardy-Weinberg equilibrium; UTR, untranslated region; MAF, minor allele frequency; CHB, Han Chinese in Beijing. 
Table 3 NGFR SNPs and the risk of Alzheimer's

\begin{tabular}{|c|c|c|c|c|c|c|c|c|}
\hline \multirow{3}{*}{ SNP } & \multicolumn{8}{|c|}{ Co-dominant model } \\
\hline & \multicolumn{2}{|c|}{0 copies } & \multicolumn{3}{|c|}{1 copy } & \multicolumn{3}{|c|}{2 copies } \\
\hline & Case/control & OR & Case/control & OR $(95 \% \mathrm{Cl})$ & $p$ & Case/control & OR $(95 \% \mathrm{Cl})$ & $p$ \\
\hline rs2072445 & $223 / 337$ & 1.00 & $41 / 48$ & $1.31(0.76-2.28)$ & 0.98 & $0 / 4$ & NA & \\
\hline rs2072446 & $208 / 306$ & 1.00 & $52 / 79$ & $1.43(0.86-2.37)$ & 0.60 & $4 / 4$ & $3.32(0.65-16.85)$ & 0.22 \\
\hline rs734194 & 146/196 & 1.00 & $103 / 160$ & $0.79(0.52-1.20)$ & 0.48 & $15 / 33$ & $0.43(0.20-0.95)$ & 0.06 \\
\hline rs741072 & $110 / 157$ & 1.00 & 118/192 & $1.02(0.67-1.56)$ & 0.67 & $36 / 40$ & $1.10(0.59-2.06)$ & 0.64 \\
\hline rs741073 & $145 / 222$ & 1.00 & $105 / 151$ & $1.04(0.69-1.57)$ & 0.26 & $14 / 16$ & $2.04(0.82-5.09)$ & 0.13 \\
\hline
\end{tabular}

All models were adjusted for age, sex, education, and ApoE\& ' 4 status.

Abbreviations: $\mathrm{OR}$, odds ratio; $\mathrm{Cl}$, confidence interval; $\mathrm{NA}$, not applicable.

$\left(P_{\text {interaction }}=0.04\right.$ and 0.01 , Table 6$)$. Results were not significant after controlling for FDR.

\section{Disscusion}

This is the first study exploring the association between NGFR polymorphisms and the risk of AD by using 5 htSNPs. We found that NGFR rs734194 was significantly associated with a decreased risk of $\mathrm{AD}$, but this was not observed in the only previous study in an Italian population [11]. Possible reasons for the inconsistent findings between the Italian study [11] and ours include differences in sample size (Cozza et al. vs. ours, sporadic AD: 151 vs. 264, controls: 97 vs. 389), case selection (not available vs. incident cases), race (Italian vs. Chinese), study time period (not available vs. 2007 to 2010), mean age (AD: 65 vs. 79, controls: 64 vs. 73 ), and SNPs selected (4 functional SNPs vs. 5 htSNPs). This is also the only Asian study up to date. In addition, no significant association was observed for NGFR rs2072445 (in intron), rs2072446 (in exon), and rs741072 [in 3' untranslated region (UTR)], which is consistent with the findings of the Italian study [11]. rs741073 has not been explored for AD risk previously and was not associated with $A D$ risk in our study. Although 5 htSNPs are in strong linkage disequilibrium
(LD; i.e., high pairwise D' as shown in dark gray, Figure 1) and located within the same haplotype block, the pairwise correlation $\left(\mathrm{r}^{2}\right)$ between rs734194 (SNP3) and any other SNP is quite low (SNP1:0.02, SNP2: 0.04, SNP4: 0.20, SNP5: 0.10, Figure 1).

Cholinergic hypothesis [3,4] has been used to elucidate the role of NGFR in AD pathogenesis because of selective loss of BFCN observed in AD patients. That is, elevated expression of NGFR and decreased TrkA may activate neuron apoptosis $[29,30]$. In addition, the binding of $A \beta$ [31-33] and proNGF [9,34] to NGFR also induce neuron apoptosis. rs734194 is located on 3' UTR and thus plays an important role in regulating the mRNA stability and translational efficiency. Therefore, variations in rs734194 may reduce the expression of NGFR or the binding of NGF, $A \beta$, or proNGF to NGFR, which inactivates the neuron apoptotic signaling and leads to decreased risk of AD. It is also possible that the variations of rs734194 decrease the secretion of NGFR on BFCN and thus reduce the interaction of NGFR with $A \beta$ and proNGF, which lower the neurotoxicity and apoptosis of BFCN. All together, these mechanisms may explain the protective effect of NGFR rs734194 on the risk of AD observed in this study.

Table 4 NGFR haplotypes and the risk of Alzheimer's disease

\begin{tabular}{|c|c|c|c|c|c|c|c|c|c|}
\hline \multirow[t]{3}{*}{ Haplotype } & \multirow{3}{*}{$\begin{array}{l}\text { Frequency } \\
\text { among controls } \\
(\%)\end{array}$} & \multicolumn{8}{|c|}{ Co-dominant model } \\
\hline & & \multicolumn{2}{|c|}{0 copies } & \multicolumn{3}{|c|}{1 copy } & \multicolumn{3}{|c|}{2 copies } \\
\hline & & Case/control & OR & Case/control & OR $(95 \% \mathrm{Cl})$ & $p$ & Case/control & OR $(95 \% \mathrm{Cl})$ & $p$ \\
\hline Hap1: GCGCG & 27.8 & $148 / 203$ & 1.00 & $105 / 156$ & $0.82(0.54-1.25)$ & 0.36 & $11 / 30$ & $0.39(0.17-0.91)$ & 0.03 \\
\hline Hap2: GCTTG & 21.9 & $159 / 234$ & 1.00 & $90 / 140$ & $0.94(0.61-1.47)$ & 0.79 & $15 / 15$ & $1.01(0.42-2.42)$ & 0.99 \\
\hline Hap3: GCTTA & 11.5 & 205/305 & 1.00 & $56 / 78$ & $1.09(0.65-1.84)$ & 0.74 & $3 / 6$ & $1.38(0.27-6.97)$ & 0.70 \\
\hline Hap4: GCTCA & 11.3 & 197/304 & 1.00 & $65 / 81$ & $1.37(0.83-2.27)$ & 0.22 & $2 / 4$ & $0.94(0.11-7.94)$ & 0.95 \\
\hline Hap5: GTTCG & 10.3 & $213 / 312$ & 1.00 & $47 / 74$ & $1.37(0.81-2.33)$ & 0.23 & $4 / 3$ & $3.59(0.66-19.42)$ & 0.14 \\
\hline Hap6: GCTCG & 8.9 & $217 / 323$ & 1.00 & $46 / 63$ & $0.97(0.54-1.73)$ & 0.92 & $1 / 3$ & $0.18(0.01-5.26)$ & 0.32 \\
\hline Hap7: TCTCG & 5.6 & 230/347 & 1.00 & $34 / 40$ & $1.15(0.63-2.12)$ & 0.65 & $0 / 2$ & NA & \\
\hline
\end{tabular}

Global test $P=0.27$

All models were adjusted for age, sex, education, and ApoE e4 status.

Global test was testing for the null hypothesis that none of the haplotype was associated with $A D$ risk.

Abbreviations: $\mathrm{OR}$, odds ratio; $\mathrm{Cl}$, confidence interval; $\mathrm{NA}$, not applicable. 
Table 5 Effect modification by type 2 diabetes on the association between NGFR genotype and the risk of Alzheimer's disease stratified by ApoE\&`4 status

\begin{tabular}{|c|c|c|c|c|c|}
\hline & \multicolumn{2}{|c|}{ NGFRnon-variant carriers } & \multicolumn{2}{|c|}{ NGFR variant carriers } & \multirow[t]{2}{*}{$P_{\text {interaction }}$} \\
\hline & Case/control & OR & Case/control & OR $(95 \% \mathrm{Cl})$ & \\
\hline \multicolumn{6}{|l|}{ ApoEs '4 non-carriers } \\
\hline \multicolumn{6}{|l|}{ rs2072445 } \\
\hline Diabetes & $25 / 40$ & 1.00 & $6 / 4$ & $5.53(0.53-57.61)$ & \\
\hline Without diabetes & $104 / 250$ & 1.00 & $20 / 35$ & $1.43(0.70-2.92)$ & 0.16 \\
\hline \multicolumn{6}{|l|}{ rs2072446 } \\
\hline Diabetes & $26 / 26$ & 1.00 & $5 / 18$ & $0.48(0.12-1.98)$ & \\
\hline Without diabetes & $89 / 227$ & 1.00 & $35 / 58$ & $2.18(1.19-4.00)$ & $0.007^{*}$ \\
\hline \multicolumn{6}{|l|}{ rs734194 } \\
\hline Diabetes & $23 / 23$ & 1.00 & $8 / 21$ & $0.28(0.08-0.98)$ & \\
\hline Without diabetes & $62 / 144$ & 1.00 & $62 / 141$ & $0.87(0.52-1.45)$ & 0.14 \\
\hline \multicolumn{6}{|l|}{ rs741072 } \\
\hline Diabetes & $8 / 21$ & 1.00 & $23 / 23$ & $2.97(0.91-9.74)$ & \\
\hline Without diabetes & $56 / 113$ & 1.00 & $68 / 172$ & $0.85(0.50-1.43)$ & 0.04 \\
\hline \multicolumn{6}{|l|}{ rs741073 } \\
\hline Diabetes & $14 / 27$ & 1.00 & $17 / 17$ & $1.84(0.57-5.89)$ & \\
\hline Without diabetes & $71 / 154$ & 1.00 & $53 / 131$ & $0.96(0.57-1.61)$ & 0.39 \\
\hline \multicolumn{6}{|l|}{ ApoE $\& 4$ carriers } \\
\hline \multicolumn{6}{|l|}{ rs2072445 } \\
\hline Diabetes & $12 / 5$ & 1.00 & $4 / 1$ & NA & \\
\hline Without diabetes & $81 / 38$ & 1.00 & 10/11 & $0.49(0.16-1.46)$ & NA \\
\hline \multicolumn{6}{|l|}{ rs2072446 } \\
\hline Diabetes & $13 / 4$ & 1.00 & $3 / 2$ & NA & \\
\hline Without diabetes & $79 / 44$ & 1.00 & $12 / 5$ & $1.49(0.36-6.21)$ & NA \\
\hline \multicolumn{6}{|l|}{ rs734194 } \\
\hline Diabetes & $7 / 3$ & 1.00 & $9 / 3$ & $2.55(0.20-33.18)$ & \\
\hline Without diabetes & $52 / 25$ & 1.00 & $39 / 24$ & $0.63(0.28-1.46)$ & 0.69 \\
\hline \multicolumn{6}{|l|}{ rs741072 } \\
\hline Diabetes & $11 / 4$ & 1.00 & $5 / 2$ & $2.09(0.15-29.98)$ & \\
\hline Without diabetes & $35 / 19$ & 1.00 & $56 / 30$ & $1.13(0.47-2.69)$ & 0.93 \\
\hline \multicolumn{6}{|l|}{ rs741073 } \\
\hline Diabetes & $8 / 5$ & 1.00 & $8 / 1$ & NA & \\
\hline Without diabetes & $51 / 31$ & 1.00 & $40 / 18$ & $1.24(0.54-2.86)$ & NA \\
\hline
\end{tabular}

All models were adjusted for age, sex, and education.

Abbreviations: OR, odds ratio; $\mathrm{Cl}$, confidence interval; NA, not applicable.

*Result remained significant after controlling for FDR.

We found that Hap1 GCGCG was significantly associated with a decreased risk of AD. rs734194 is the only SNP carrying the variant allele in Hap1. Therefore, the significant association of Hap1 and AD may be attributable to rs734194. It is also possible that other rare polymorphisms not analyzed here are responsible for the association observed. Our finding was not comparable to the Italian study [11] because fewer SNPs were selected and no significant association was observed for NGFR haplotypes in that study.

This study found that type 2 DM significantly modified the association between NGFR polymorphisms and the risk of $\mathrm{AD}$ in $A p o E \& 4$ non-carriers. It is possible that type
$2 \mathrm{DM}$ modifies the association between NGFR and $\mathrm{AD}$ via the following mechanisms: (1) hyperglycemia [35-37], (2) altered insulin level and sensitivity in the brain [13,38-40], and (3) diabetes-related vascular diseases, e.g., hypertension and arterial disease [41]. In addition, $A p o E \varepsilon 4$ status affects cholesterol metabolism and may act together with $\mathrm{DM}$ to modulate the risk of $\mathrm{AD}$ [42-44]. The significant effect modification was only observed in $A p o E \& 4$ non-carriers, which may be due to the counteracting effect between $A p o E \& 4$ allele (increase AD risk) and variant of NGFR (protective effect) on AD risk.

This study has some strengths. No study has investigated the role of NGFR polymorphisms on the risk of 
Table 6 Effect modification by type 2 diabetes on the association between NGFR haplotypes and the risk of Alzheimer's disease stratified by ApoEs `4 status

\begin{tabular}{|c|c|c|c|c|c|}
\hline & \multicolumn{2}{|c|}{ NGFR variant non-carriers } & \multicolumn{2}{|c|}{ NGFR variant carriers } & \multirow[t]{2}{*}{$P_{\text {interaction }}$} \\
\hline & Case/control & OR & Case/control & OR $(95 \% \mathrm{Cl})$ & \\
\hline \multicolumn{6}{|l|}{ ApoEs `4 non-carriers } \\
\hline \multicolumn{6}{|l|}{ Hap1: GCGCG } \\
\hline Diabetes & $23 / 23$ & 1.00 & $8 / 21$ & $0.28(0.08-0.97)$ & \\
\hline Without diabetes & $64 / 151$ & 1.00 & $60 / 134$ & $0.90(0.53-1.51)$ & 0.12 \\
\hline \multicolumn{6}{|l|}{ Hap2: GCTTG } \\
\hline Diabetes & $15 / 29$ & 1.00 & $17 / 15$ & $2.79(0.83-9.43)$ & \\
\hline Without diabetes & $83 / 173$ & 1.00 & $41 / 112$ & $0.73(0.42-1.26)$ & 0.04 \\
\hline \multicolumn{6}{|l|}{ Hap3: GCTTA } \\
\hline Diabetes & $22 / 34$ & 1.00 & $9 / 10$ & $1.17(0.30-4.51)$ & \\
\hline Without diabetes & $95 / 220$ & 1.00 & $29 / 65$ & $1.11(0.57-2.14)$ & 0.94 \\
\hline \multicolumn{6}{|l|}{ Hap4: GCTCA } \\
\hline Diabetes & $22 / 36$ & 1.00 & $9 / 8$ & $1.91(0.42-8.78)$ & \\
\hline Without diabetes & $93 / 217$ & 1.00 & $31 / 68$ & $1.12(0.59-2.11)$ & 0.43 \\
\hline \multicolumn{6}{|l|}{ Hap5: GTTCG } \\
\hline Diabetes & $26 / 27$ & 1.00 & $5 / 17$ & $0.50(0.12-2.09)$ & \\
\hline Without diabetes & $92 / 232$ & 1.00 & $32 / 53$ & $2.12(1.13-3.99)$ & 0.01 \\
\hline \multicolumn{6}{|l|}{ Hap6: GCTCG } \\
\hline Diabetes & $26 / 39$ & 1.00 & $5 / 5$ & $2.50(0.32-19.61)$ & \\
\hline Without diabetes & $111 / 234$ & 1.00 & $13 / 51$ & $0.48(0.21-1.10)$ & 0.06 \\
\hline \multicolumn{6}{|l|}{ Hap7: TCTCG } \\
\hline Diabetes & $25 / 41$ & 1.00 & $6 / 3$ & $7.15(0.55-93.39)$ & \\
\hline Without diabetes & $109 / 257$ & 1.00 & $14 / 28$ & $1.10(0.48-2.54)$ & 0.23 \\
\hline \multicolumn{6}{|l|}{ ApoE\&4 carriers } \\
\hline \multicolumn{6}{|l|}{ Hap1: GCGCG } \\
\hline Diabetes & $7 / 3$ & 1.00 & $9 / 3$ & $2.53(0.19-33.57)$ & \\
\hline Without diabetes & $52 / 25$ & 1.00 & $39 / 24$ & $0.64(0.28-1.48)$ & 0.71 \\
\hline \multicolumn{6}{|l|}{ Hap2: GCTTG } \\
\hline Diabetes & $12 / 4$ & 1.00 & $4 / 2$ & $2.17(0.13-35.20)$ & \\
\hline Without diabetes & $48 / 28$ & 1.00 & $43 / 21$ & $1.04(0.42-2.57)$ & 0.82 \\
\hline \multicolumn{6}{|l|}{ Hap3: GCTTA } \\
\hline Diabetes & $15 / 6$ & 1.00 & $1 / 0$ & NA & \\
\hline Without diabetes & $72 / 40$ & 1.00 & $19 / 9$ & $1.43(0.47-4.31)$ & NA \\
\hline \multicolumn{6}{|l|}{ Hap4: GCTCA } \\
\hline Diabetes & $9 / 5$ & 1.00 & $7 / 1$ & NA & \\
\hline Without diabetes & $70 / 41$ & 1.00 & $21 / 8$ & $1.49(0.48-4.60)$ & NA \\
\hline \multicolumn{6}{|l|}{ Hap5: GTTCG } \\
\hline Diabetes & $13 / 4$ & 1.00 & $3 / 2$ & NA & \\
\hline Without diabetes & $80 / 44$ & 1.00 & $11 / 5$ & $1.48(0.35-6.26)$ & NA \\
\hline \multicolumn{6}{|l|}{ Hap6: GCTCG } \\
\hline Diabetes & $13 / 4$ & 1.00 & $3 / 2$ & NA & \\
\hline Without diabetes & $66 / 41$ & 1.00 & $25 / 8$ & $2.42(0.74-7.95)$ & NA \\
\hline \multicolumn{6}{|l|}{ Hap7: TCTCG } \\
\hline Diabetes & $12 / 5$ & 1.00 & $4 / 1$ & NA & \\
\hline Without diabetes & $82 / 39$ & 1.00 & $9 / 10$ & $0.53(0.16-1.72)$ & NA \\
\hline
\end{tabular}

All models were adjusted for age, sex, and education.

Abbreviations: OR, odds ratio; $\mathrm{Cl}$, confidence interval; $\mathrm{NA}$, not applicable. 
$\mathrm{AD}$ using a set of representative htSNPs and their corresponding haplotypes. In this study, 5 htSNPs were selected via a systematic approach and captured over $85 \%$ of genetic information in NGFR (estimated by tagSNP program). In contrast, the only prior study [11] assessed 4 NGFR SNPs, which capture only $14 \%$ of genetic information in the gene. Second, the sample size of our study is larger than the Italian study (Cozza et al. vs. ours, sporadic AD: 151 vs. 264, controls: 97 vs. 389). In addition, this study has over $90 \%$ power to detect an OR of 0.43 for the main effect and $78 \%$ power to detect an OR of 0.28 for the interaction between NFGR and type $2 \mathrm{DM}$ on the risk of AD. Third, no study has assessed this association in Chinese population and identified NGFR SNPs representative for this ethnic group. Last, the use of brain image increased the validity of $\mathrm{AD}$ ascertainment and reduced misclassification of disease subtypes.

This study has some limitations. DM status was selfreported and thus may be biased. However, in our questionnaire, this information was further confirmed by asking if there was a previous diagnosis or taking medications for type $2 \mathrm{DM}$ after seeing a doctor. Because $\mathrm{DM}$ is a major disease, participants' recall of DM diagnosis and their awareness of DM should be relatively accurate [45-47]. As a whole, the chance of recall bias was low.

In summary, this study found that NGFR htSNPs and haplotypes were associated with AD risk. Type $2 \mathrm{DM}$ significantly modified the association between NGFR polymorphisms and the risk of AD in ApoE $\varepsilon 4$ non-carriers. Although these findings did not reach statistical significance after correction for multiple tests, it is possible that the NFGR polymorphisms were associated with familial AD. This is because NGFR rs2072446 was associated with a decreased risk of familial AD in the Italian study [11]. Most of sporadic AD cases are $A p o E$ $\varepsilon 4$ non-carriers $(60 \%)$ observed in this and other studies, therefore, our findings shed light on the importance of identifying genetic markers in $A p o E \& 4$ non-carriers. Future large studies are warranted to confirm our findings.

\section{Acknowledgements}

Funding for the study was provided by the National Science Council grants NSC 96-2314-B-002 -197 and NSC 97-2314-B-002-168-MY3.

\footnotetext{
Author details

${ }^{1}$ Institute of Epidemiology and Preventive Medicine, College of Public Health, National Taiwan University, Taipei, Taiwan. ${ }^{2}$ Department of Neurology, En Chu Kong Hospital, Taipie, Taiwan. ${ }^{3}$ Graduate Institute of Physiology, College of Medicine, National Taiwan University, Taipei, Taiwan. ${ }^{4}$ Research Center for Genes, Environment and Human Health, Taipei, Taiwan. ${ }^{5}$ Department of Public Health, College of Public Health, National Taiwan University, Taipei, Taiwan. ${ }^{6}$ Department of Geriatrics and Gerontology, National Taiwan University Hospital, Taipei, Taiwan. ${ }^{7}$ Department of Neurology, National
}

Taiwan University Hospital, Taipei, Taiwan. ${ }^{8}$ Department of Laboratory Medicine, En Chu Kong Hospital, Taipie, Taiwan. ${ }^{9}$ Center of Neurological Medicine, Cardinal Tien's Hospital, Taipie, Taiwan. ${ }^{10}$ Department of Laboratory Medicine, Cardinal Tien's Hospital, Taipie, Taiwan.

\section{Authors' contributions}

HCC: data analyses and manuscript writing; YS: participant recruitment; LCL: technical review; SYC: data analyses; WCL: technical review; JHC: participant recruitment and study design; TFC: participant recruitment; $\mathrm{HHC}$ : genotyping; LLW: biospecimen collection and treatment; PKY: participant recruitment; YMC: biospecimen collection and treatment; WJC: technical review; YCC: conceived of the study, genetic data analyses, manuscript writing, and project coordination. All authors have read and approved the final manuscript.

\section{Competing interests}

The authors declare that they have no competing interests.

Received: 9 November 2011 Accepted: 12 January 2012

Published: 12 January 2012

\section{References}

1. Alzheimer's Disease Facts and Figures. Alzheimer's \& Dementia. 2010 [http://www.alz.org/alzheimers_disease_facts_figures.asp?type=homepage]

2. Dementia sufferer numbers increasing in Taiwan. [http://www. globalaging.org/health/world/2009/dementiasufferer.htm]

3. Davies P, Maloney AJ: Selective loss of central cholinergic neurons in Alzheimer's disease. Lancet 1976, 2(8000):1403.

4. Boissiere F, Lehericy S, Strada O, Agid Y, Hirsch EC: Neurotrophin receptors and selective loss of cholinergic neurons in Alzheimer disease. $\mathrm{Mol}$ Chem Neuropathol 1996, 28(1-3):219-223.

5. Hefti F, Mash DC: Localization of nerve growth factor receptors in the normal human brain and in Alzheimer's disease. Neurobiol Aging 1989, 10(1):75-87.

6. Woolf NJ, Gould E, Butcher LL: Nerve growth factor receptor is associated with cholinergic neurons of the basal forebrain but not the pontomesencephalon. Neuroscience 1989, 30(1):143-152.

7. Chao MV, Hempstead BL: p75 and Trk: a two-receptor system. Trends Neurosci 1995, 18(7):321-326.

8. Lad SP, Neet KE, Mufson EJ: Nerve growth factor: structure, function and therapeutic implications for Alzheimer's disease. Curr Drug Targets CNS Neurol Disord 2003, 2(5):315-334.

9. Lee R, Kermani P, Teng KK, Hempstead BL: Regulation of cell survival by secreted proneurotrophins. Science 2001, 294(5548):1945-1948.

10. Knowles JK, Rajadas J, Nguyen TV, Yang T, LeMieux MC, Van der Griend L, Ishikawa C, Massa SM, Wyss-Coray T, Longo FM: The p75 neurotrophin receptor promotes amyloid-beta(1-42)-induced neuritic dystrophy in vitro and in vivo. J Neurosci 2009, 29(34):10627-10637.

11. Cozza A, Melissari E, lacopetti P, Mariotti V, Tedde A, Nacmias B, Conte A, Sorbi S, Pellegrini S: SNPs in neurotrophin system genes and Alzheimer's disease in an Italian population. J Alzheimers Dis 2008, 15(1):61-70.

12. $L i Z G$, Zhang W, Sima AA: The role of impaired insulin/IGF action in primary diabetic encephalopathy. Brain Res 2005, 1037(1-2):12-24.

13. Ott A, Stolk RP, van Harskamp F, Pols HA, Hofman A, Breteler MM: Diabetes mellitus and the risk of dementia: The Rotterdam Study. Neurology 1999, 53(9):1937-1942.

14. Fontbonne A, Berr C, Ducimetiere $P$, Alperovitch A: Changes in cognitive abilities over a 4-year period are unfavorably affected in elderly diabetic subjects: results of the Epidemiology of Vascular Aging Study. Diabetes Care 2001, 24(2):366-370

15. Janson J, Laedtke T, Parisi JE, O'Brien P, Petersen RC, Butler PC: Increased risk of type 2 diabetes in Alzheimer disease. Diabetes 2004, 53(2):474-481.

16. Schuelke M, Mayatepek E, Inter M, Becker M, Pfeiffer E, Speer A, Hubner C, Finckh B: Treatment of ataxia in isolated vitamin $E$ deficiency caused by alpha-tocopherol transfer protein deficiency. J Pediatr 1999, 134(2):240-244.

17. Morris J: The Clinical Dementia Rating (CDR): current version and scoring rules. Neurology 1993, 43(11):2412-2414.

18. Cataliotti A, Chen HH, Redfield MM, Burnett JC Jr: Natriuretic peptides as regulators of myocardial structure and function: pathophysiologic and therapeutic implications. Heart Fail Clin 2006, 2(3):269-276. 
19. Burton EJ, Barber R, Mukaetova-Ladinska EB, Robson J, Perry RH, Jaros E, Kalaria RN, O'Brien JT: Medial temporal lobe atrophy on MRI differentiates Alzheimer's disease from dementia with Lewy bodies and vascular cognitive impairment: a prospective study with pathological verification of diagnosis. Brain 2009, 132(Pt 1):195-203.

20. Pfeiffer $\mathrm{E}$ : A short portable mental status questionnaire for the assessment of organic brain deficit in elderly patients. J Am Geriatr Soc 1975, 23(10):433.

21. Gabriel SB, Schaffner SF, Nguyen H, Moore JM, Roy J, Blumenstiel B, Higgins J, DeFelice M, Lochner A, Faggart M, et al: The structure of haplotype blocks in the human genome. Science 2002, 296(5576):2225-2229.

22. Chen YC, Giovannucci E, Lazarus R, Kraft P, Ketkar S, Hunter DJ: Sequence variants of Toll-like receptor 4 and susceptibility to prostate cancer. Cancer Res 2005, 65(24):11771-11778.

23. Stram DO, Leigh Pearce C, Bretsky P, Freedman M, Hirschhorn JN, Altshuler D, Kolonel LN, Henderson BE, Thomas DC: Modeling and E-M estimation of haplotype-specific relative risks from genotype data for a case-control study of unrelated individuals. Hum Hered 2003, 55(4):179-190.

24. Chapman J, Estupinan J, Asherov A, Goldfarb LG: A simple and efficient method for apolipoprotein E genotype determination. Neurology 1996, 46(5):1484-1485.

25. Corder EH, Saunders AM, Strittmatter WJ, Schmechel DE, Gaskell PC, Small GW, Roses AD, Haines $J$, Pericak-Vance MA: Gene dose of apolipoprotein E type 4 allele and the risk of Alzheimer's disease in late onset families. Science 1993, 261(5123):921-923.

26. Chartier-Harlin MC, Parfitt M, Legrain S, Perez-Tur J, Brousseau T, Evans A, Berr C, Vidal O, Roques $P$, Gourlet $V$, et al: Apolipoprotein $E$, epsilon 4 allele as a major risk factor for sporadic early and late-onset forms of Alzheimer's disease: analysis of the 19q13.2 chromosomal region. Hum Mol Genet 1994, 3(4):569-574

27. Azad NA, Al Bugami M, Loy-English I: Gender differences in dementia risk factors. Gend Med 2007, 4(2):120-129.

28. Schmidt R, Kienbacher E, Benke T, Dal-Bianco P, Delazer M, Ladurner G,

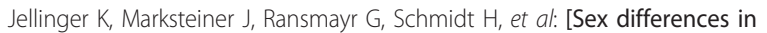
Alzheimer's disease]. Neuropsychiatr 2008, 22(1):1-15.

29. Counts SE, Nadeem M, WuU J, Ginsberg SD, Saragovi HU, Mufson EJ: Reduction of cortical TrkA but not p75(NTR) protein in early-stage Alzheimer's disease. Ann Neurol 2004, 56(4):520-531.

30. Counts SE, Mufson EJ: The role of nerve growth factor receptors in cholinergic basal forebrain degeneration in prodromal Alzheimer disease. J Neuropathol Exp Neurol 2005, 64(4):263-272.

31. Yaar M, Zhai S, Pilch PF, Doyle SM, Eisenhauer PB, Fine RE, Gilchrest BA: Binding of beta-amyloid to the $p 75$ neurotrophin receptor induces apoptosis. A possible mechanism for Alzheimer's disease. J Clin Invest 1997, 100(9):2333-2340.

32. Tsukamoto E, Hashimoto $Y$, Kanekura K, Niikura T, Aiso S, Nishimoto I: Characterization of the toxic mechanism triggered by Alzheimer's amyloid-beta peptides via p75 neurotrophin receptor in neuronal hybrid cells. J Neurosci Res 2003, 73(5):627-636.

33. Coulson EJ, May LM, Sykes AM, Hamlin AS: The role of the p75 neurotrophin receptor in cholinergic dysfunction in Alzheimer's disease. Neuroscientist 2009, 15(4):317-323.

34. Al-Shawi R, Hafner A, Chun S, Raza S, Crutcher K, Thrasivoulou C, Simons P, Cowen T: ProNGF, sortilin, and age-related neurodegeneration. Ann N Y Acad Sci 2007, 1119:208-215.

35. Gispen WH, Biessels GJ: Cognition and synaptic plasticity in diabetes mellitus. Trends Neurosci 2000, 23(11):542-549.

36. Kanaya AM, Barrett-Connor E, Gildengorin G, Yaffe K: Change in cognitive function by glucose tolerance status in older adults: a 4-year prospective study of the Rancho Bernardo study cohort. Arch Intern Med 2004, 164(12):1327-1333.

37. Perlmuter LC, Hakami MK, Hodgson-Harrington C, Ginsberg J, Katz J, Singer DE, Nathan DM: Decreased cognitive function in aging noninsulin-dependent diabetic patients. Am J Med 1984, 77(6):1043-1048.

38. Abbatecola AM, Paolisso G, Lamponi M, Bandinelli S, Lauretani F, Launer L, Ferrucci $L$ : Insulin resistance and executive dysfunction in older persons. J Am Geriatr Soc 2004, 52(10):1713-1718.

39. Luchsinger JA, Tang MX, Shea S, Mayeux R: Hyperinsulinemia and risk of Alzheimer disease. Neurology 2004, 63(7):1187-1192.
40. Young SE, Mainous AG, Carnemolla M: Hyperinsulinemia and cognitive decline in a middle-aged cohort. Diabetes Care 2006, 29(12):2688-2693.

41. Messier C, Gagnon M: Cognitive decline associated with dementia and type 2 diabetes: the interplay of risk factors. Diabetologia 2009, 52(12):2471-2474.

42. Peila R, Rodriguez BL, Launer LJ: Type 2 diabetes, APOE gene, and the risk for dementia and related pathologies: The Honolulu-Asia Aging Study. Diabetes 2002, 51(4):1256-1262.

43. Dore GA, Elias MF, Robbins MA, Elias PK, Nagy Z: Presence of the APOE epsilon4 allele modifies the relationship between type 2 diabetes and cognitive performance: the Maine-Syracuse Study. Diabetologia 2009, 52(12):2551-2560.

44. Irie F, Fitzpatrick AL, Lopez OL, Kuller LH, Peila R, Newman AB, Launer LJ: Enhanced risk for Alzheimer disease in persons with type 2 diabetes and APOE epsilon4: the Cardiovascular Health Study Cognition Study. Arch Neurol 2008, 65(1):89-93.

45. El Fakiri F, Bruijnzeels MA, Hoes AW: No evidence for marked ethnic differences in accuracy of self-reported diabetes, hypertension, and hypercholesterolemia. J Clin Epidemiol 2007, 60(12):1271-1279.

46. Okura Y, Urban LH, Mahoney DW, Jacobsen SJ, Rodeheffer RJ: Agreement between self-report questionnaires and medical record data was substantial for diabetes, hypertension, myocardial infarction and stroke but not for heart failure. J Clin Epidemiol 2004, 57(10):1096-1103.

47. St Sauver JL, Hagen PT, Cha SS, Bagniewski SM, Mandrekar JN, Curoe AM, Rodeheffer RJ, Roger $\mathrm{VL}$, Jacobsen SJ: Agreement between patient reports of cardiovascular disease and patient medical records. Mayo Clin Proc 2005, 80(2):203-210.

doi:10.1186/1477-5751-11-5

Cite this article as: Cheng et al:: Genetic polymorphisms of nerve growth factor receptor (NGFR) and the risk of Alzheimer's disease. Journal of Negative Results in BioMedicine 2012 11:5.

\section{Submit your next manuscript to BioMed Central and take full advantage of:}

- Convenient online submission

- Thorough peer review

- No space constraints or color figure charges

- Immediate publication on acceptance

- Inclusion in PubMed, CAS, Scopus and Google Scholar

- Research which is freely available for redistribution

Submit your manuscript at www.biomedcentral.com/submit
C Biomed Central 